\title{
Editorial
}

\section{The Digital World We Will Live By}

By Pompeu Casanovas, La Trobe University, Melbourne, Australia, Orcid: http://orcid.org/0000-0002-0980-2371

David Wishart, La Trobe University, Melbourne, Australia, Orcid: http://orcid.org/0000-0003-2281-4745

Jianfu Chen, La Trobe University, Melbourne, Australia, Orcid: http://orcid.org/0000-0002-4711-6524

\section{ABSTRACT}

This editorial provides a brief description of the digital turn experienced at the beginning of this century, the side effects of Covid-19, and the twelve commitments recently laid down by the United Nations. It introduces the concepts of 'Global Syndemic' (or synergy of epidemics), the 'Internet of Things', 'RegTech', and 'Knowledge Graphs'. Finally, it describes briefly the articles included in this issue.

Keywords - Covid-19, Global Syndemic, Digital turn, Internet of Things, RegTech, Knowledge Graphs

Disclosure statement - No potential conflict of interest was reported by the author.

License - This work is under Attribution-NonCommercial-ShareAlike 4.0 International (CC BY-NC-SA 4.0) https://creativecommons.org/licenses/ by-nc-sa/4.0/

Suggested citation: P. Casanovas, D. Wishart, and J. Chen (2020). "Editorial: The Digital World We Will Live By", Law in Context, 37 (1): 6-10, DOI: http://doi.org/10.26826/law-in-context.v37i1.136

\section{Summary}

1. The Digital World We Will Live By

2. On the Contents of this Issue: LiC 37 (1)

3. References 


\section{THE DIGITAL WORLD WE WILL LIVE BY}

LiC 37 (1) is the third Issue of the new Online Law in Context. It comes at the end of a year subject to all possible evaluation criteria. The year leaves a host of questions awaiting answers. In March 2020, when Covid-19 was already in evidence all over the world, Yuval N. Harari (2020) wrote in the Financial Times that humanity was facing two important choices, the first between totalitarian surveillance and citizen empowerment; the second between nationalist isolation and global solidarity. The US elections in November and their aftermath seem to confirm this judgement but have thrown up more questions than explanations or answers.

Many declarations, manifestos, predictions and commentaries have followed one another over the course of the past twelve months. Reflection on the effects of the present crisis has been felt as an urgent need. The United Nations celebrated its 75th Anniversary in 2020. However, as the UN meeting coverage underlined, what world leaders actually said was "we are not here to celebrate" (UNGAa). Indeed, the Declaration on the Commemoration of the Seventy-Fifth Anniversary of the United Nations, submitted by the President to the General Assembly on September 16th 2020 asserts that

"Our world is not yet the world that our founders envisaged 75 years ago. It is plagued by growing inequality, poverty, hunger, armed conflicts, terrorism, insecurity, climate change and pandemics. People in different corners of the world are forced to make dangerous journeys in search of refuge and safety. The least developed countries are falling behind, and we still have not achieved complete decolonization." (UNGA 2020b)

The text lays out twelve commitments to reanimate global resolve: leave no one behind, protect the planet, promote peace, abide by international law, place women and girls at the centre, build trust, improve digital cooperation, upgrade the United Nations, ensure sustainable financing, boost partnerships, work with youth, and, finally, be prepared. (UNGA 2020a, b)

These ideals matter and should not be ignored. We would like to stress from our side that they cannot be treated separately, for they are as connected to each other as the threats they face. They are closely tied, and if we read them in the light of Covid-19 we will soon realise that what is at stake is not just a pandemic but what health experts have called a global syndemic, i.e. a synergy of epidemics. This was already advanced by some analyses published at The Lancet in February 2019 before Covid-19 appeared in October/November of the same year, focusing on obesity, undernutrition, and climate change. This global syndemic "affects most people in every country and region worldwide" and their elements "co-occur in time and place, interact with each other to produce complex sequalae, and share common societal drivers" (Swinburn et al. 2019, p. 791). From this perspective, Covid-19 and the global response to it has accelerated the effects of a global change that was already happening, focusing especially on the Internet of Things.

Both threats and challenges are taking place in a digitised world that is not what we expected it to be only twenty-five years ago. The Internet alone cannot foster democracy, and John Perry Barlow's dreams in his widely spread Declaration of the Independence of Cyberspace (1994) did not come true. Web governance will not emerge from "ethics, enlightened self-interest, and the commonweal" (Barlow 1994, ibid.). He was visionary about the changes that cyberspace would bring. But he fell short about the evolution of technology and the difficulty to adapt and cope with a radically different environment. The IoT embraces many cyber-physical systems automatically connected, using sensors and other technologies, enabling people and all kind of devices to interact with each other and the environment on real time, and to keep track of it, i.e. collecting, storing and sharing data on an unprecedented scale. How are we going to manage, monitor and control the information processing flows that occur in the IoT?

Gartner has identified IoT applications as trending in 2021. The Internet of Things blends the physical and digital worlds and is transforming the way we live and work. According to it, workplaces of the future will evolve in response to the pandemic "regardless of whether they are offices for knowledge workers or automobile manufacturing plants" (Gartner 2020). This holds for education, universities, research centres, and what has been termed "digital twins". Digital twins-digital replicas of a living or non-living entity in the IoT-are a potential transformative technology for everything from devices to 
cities, but standards or common integration frameworks do not yet exist for digital twin data, models, analytics or security (Gartner 2020).

We are only now coming to understand that something else is required to produce a fair society, the effective enactment of civil rights, and a political acceptable world in digital environments. Embedding the rule of law into the structures of the Internet of Things is not enough either, as the IoT is able to change the market, the way how contracts are drafted and executed, the way how laws can be drafted and enacted, and our own understanding of what comprises law and regulations.

According to a recent report of the Cambridge Centre for Alternative Finance, industry forecasts for RegTech companies point to year-on-year growth of between 23\% and 25\% between 2018 and 2023 (Swinburn et al. 2019, 11). RegTech - LawTech, FinTech, SupTech, InsuTech-companies and web services are offering profiling and due diligence, dynamic compliance by design, risk analysis and data analytics to corporations, companies, public administrations, and law firms. Technology and the emergence of these new specialised legal markets are impacting on the structure, form and content of legal practice to an extent that has yet to be determined. For instance, GPT-3 is trained on 410 billion tokens and has 175 billion parameters. Would it replace lawyers in a non-distant future?

The legal field usually reacts with extreme prudence to this kind of suggestions. But there are some authorised voices that are betting on it. GPT-3 learns how to predict the next word from reading literally billions of texts. If it can be fed and trained with cases and legal arguments (and it can), and it can be easily enriched with technical annotations (and it can), then it will attract investors and it will be used in the legal field for professional and legal purposes, and subsequently other computer programs will follow. Legal professionals are "like traffic cops just before the roll-out of traffic lights", just before being replaced by "AutoLaw, where machines guide us through conflicts the way traffic lights help us avoid collisions" (Blijd 2020).

A fictional dystopic future perhaps? Maybe. What is certain is that legal doctrine (either in private, public, international and transnational law), socio-legal research, and legal education should acknowledge what is happening and react accordingly.

\section{ON THE CONTENTS OF THIS ISSUE: LIC 37 (1)}

In the first volume of Law in Context online, LiC 36 (1), we set a common ground for Law \& Society and AI \& Law. We pointed at the concept of legal knowledge as a research subject (Casanovas, Chen and Wishart 2019), and we contended the urgent necessity of a joint tight cooperation between the two fields. The second Issue 36 (2) represented another step in this direction, strengthening some LiC values and beliefs on the relevance of gender, history, and human rights (Savitri 2020).

This third volume is a new step. It is not a special issue on technology, rather it gathers some relevant works which consistently try to shed light on some contemporary problems of this hybrid world arising from human, institutional, and technological changes. LiC 37 (1) contains seven original Research Articles, two relevant Research Notes, and four Book Reviews.

Ugo Pagallo opens the Issue with an article on the legal and political impact of the Covid-19 crisis, drawing the attention to fundamental questions on authority and political legitimacy, coercion and obligation, power and cooperation. He depicts the regulatory environment of the Web of Data and the Internet of Things, which is significantly pertinent to present the volume.

Daniel Schwabe, Carlos Laufer and Pompeu Casanovas introduce the notion of Knowledge Graph as a legal governance framework to support trust, privacy, transparency and accountability. Stemming from the Web of Data, Knowledge Graphs (KG) represent a graph-theoretic representation of human knowledge such that it can be ingested with semantics by a machine (Fensel et al. 2020). The authors show that it is an especially suitable tool for regulatory purposes on the Internet of Things.

Vanessa Teague's and Patrick Keyzer's work comes as a hot topic, after the American presidential elections and its aftermath in November and December 2020. Their work is an example of felicitous cooperation between a computer scientist and a constitutional lawyer. The authors delve on the conditions that would make electronic Australian elections safe and acceptable. Electronic voting 
and counting have been adopted in a number of Australian jurisdictions, but there is evidence that e-voting systems lack transparency. The authors argue that source code and the voting data should be made available for testing and recommend several appropriate legislative reforms.

The next article also relates to Australia, focusing on human rights and identity groups. In its nature, it is a piece of comparative law. H. W. Perry Jr. and Patrick Keyzer examine the role of amicus curiae procedures in the United States Supreme Court and consider whether they can be adopted by the High Court of Australia. They contend that human rights cases raise questions of minority rights that should not be adjudicated without input from those minorities. It is then aligned with the Constitutional Open Rights interpretation pointed out by Keyzer (2010). The authors recommend admitting written submissions and allowing applicants to make oral submissions.

Likewise, Natalia Antolak-Saper's article focuses on some social practices and institutional actions that affects minorities. This time, it is about youth offenders in the Victorian Juvenile Justice system. The author examines the process of 'adultification' of the system, after a historical examination of the Victorian model. The article shows the role of the media in advocating the imposition of a 'tough on crime' approach that have been assumed and implemented by the Victorian State Government without a sound evaluation, and contends that this kind of policy is not only ineffective but inconsistent with the best interests of the child.

The two last Research articles can be presented alike, although they have been submitted separately, and they apparently deal with two very different subjects in the field of legal education in the contemporary world. It is an example of how beneficial it could be to explore new ways of teaching law and practices stemming from both a critical reading from a socio-legal approach, and the new technological toolkit that it is required to understand and operate into the Internet of Things. Both articles deal with present true teaching experiences, drawing lessons learned from them.

The experience of Barry Young and David Catanzariti is located at the Australian National University, in Canberra. The authors carry out a qualitative analysis on the attitudes and perceptions of law students, contrasted against the reflections of early career commercial lawyers about their school experiences. Pierre Bourdieu's (1984) notions of power and distinction are used as focal lens to understand students' perceptions and to contend that their assorted ambitions would require a Law School environment promoting a more diversified and accurate perspective of what 'real practice' consists of.

Jaromir Savelka, Matthias Grabmair and Kevin D. Ashley describe the structure and contents of a new Law School course in applied legal analytics and Artificial Intelligence. The course took place in the University of Pittsburgh, in Pennsylvania, USA, and the authors thoroughly explain how Machine Learning (ML) and Natural Language Processing (NLP) techniques can be taught to combined groups of law students and students from technical departments. In the same practical way used in Ashley (2017), this course explores some effective strategies and exercises to furnish to the students the required skills and knowledge to deal with the new RegTech toolkit. As the authors explain, the course culminated in joint projects engaging joint small teams in applying machine learning and data analytics to legal problems. The results of two of them have been accepted for presentation at JURIX 2020 and already published (Gretok, Langerman and Oliver 2020; $\mathrm{Xu}$, Šavelka and Ashley 2020).

This Issue also apprises the readers about two interesting research initiatives that are just emerging in the legal field. They are published as Research Notes, i.e. short papers explaining processes, results and findings of specific research trends.

The first one, by Víctor Rodríguez-Doncel and Elena Montiel-Ponsoda, deploys the results of the ongoing H2020 Project, LYNX, Legal Knowledge Graph for Multilingual Compliance Services. This is an example of what can be done to facilitate legal compliance through a collection of services, implementing natural language techniques, better legal information retrieval and cross-lingual answering of questions and information discovery.

The second one, by Mathew Waddington, is an elaborated and reflective response to the brief recently published at The Conversation (Governatori et al. 2020) on the recent movement called Rules as Code. It is also an 
invitation to discussion and dialogue with legal scholars and legal professionals. To our opinion, this is one of the best descriptions the reader can find about the aims and development of this recent government trend that attempts to draft and serve laws using both coding and natural language.

Finally, LiC 37 (1) closes with four reviews of books published in 2020: by Woodrow Barfield and Ugo Pagallo (Stephanie Falconer), by Anne Wesemann (David Wishart), by Jan Wouters and members of the Leuven Centre for Global Governance Studies (Emma Henderson), and by Kerry King (Robert P. Brown). Again, these volumes are a good sample of the researches covered by our Journal on Human Rights, International Law, Law and Technology, and Criminology.

Finally, we would like to thank, in alphabetical order, Nishali Paththamperuma Arachchige, Alessandra Burato, Samuel Fenton, Madeleine E. Gome, Kelsey Kropf, and Christina Michael for their valuable work with this edition. We deem the support of our recently created LiC Student Editorial Board essential to help both authors and readers with Issues to come.

\section{REFERENCES}

1. Ashley, K.D. 2017. Artificial intelligence and legal analytics: new tools for law practice in the digital age. Cambridge: Cambridge University Press.

2. Blijd, R. 2020. "Will lawyers be replaced by GPT-3? Yes, and here's when." September 7. https://www.legalcomplex.com/2020/09/07/ will-lawyers-be-replaced-by-gpt-3-yes-and-heres-when/

3. Bourdieu, P. 1984. Distinction: A social critique of the judgement of taste. Cambridge, Mass.: Harvard University Press.

4. Casanovas, P., Chen, J. and Wishart, D., 2019. "Law in Context for the Digital Age", Law in Context. A Socio-legal Journal, 36 (1): 3-11.

5. Fensel, D. Şimşek, U., Angele, K., Huaman, E., Kärle, E., Panasiuk, O., Toma, I., Umbrich, J. and Wahler, A., 2020. Knowledge Graphs. Methodology, Tools and Selected Use Cases. Cham: Springer International Publishing.

6. Gartner. 2020. "Interactive hypecycle for the Internet of Things". https://www.gartner.com/document/3987602 ?ref=solrAll\&refval=272631259
7. Governatori, G., Barneys, J., de Koker, L., Poblet, M. Hashmi, M., Zeleznikow, J. Casanovas, P. 2020. "'Rules as Code' will let computers apply laws and regulations. But over-rigid interpretations would undermine our freedoms." The Conversation, 26 November, https://theconversation. com/rules-as-code-will-let-computers-apply-lawsand-regulations-but-over-rigid-interpretations-wouldundermine-our-freedoms-149992

8. Gretok, E., Langerman, D., and Oliver, W.M. 2020. "Transformers for Classifying Fourth Amendment Elements and Factors Tests", In Villata, S., Harašta, J., and Křemen, P. (eds.) Legal Knowledge and Information Systems JURIX 2020: The Thirty-third Annual Conference, IOS Press: Amsterdam, pp. 63-72.

9. Harari, Y.N. 2020. "The world after coronavirus", Financial Times, March 20. https://www.ft.com/ content/19d90308-6858-11ea-a3c9-1fe6fedcca75

10. Keyzer, P. 2010. Open Constitutional Courts. Melbourne: Federation Press.

11. Schizas, E., McKain, G., Zhang, B.Z., Garvey, K., Ganbold, A., Hussain, H., Kumar, P., Huang, E., Wang, S. and Yerolemou, N. 2019. "The Global RegTech Industry Benchmark Report". Available at SSRN 3560811.

12. Swinburn, B.A., Kraak, V.I., Allender, S., Atkins, V.J., Baker, P.I., Bogard, J.R., Brinsden H., Calvillo, A., de Schutter, O., Devarajan, R., Ezzati, M. 2019. "The Global Syndemic of Obesity, Undernutrition, and Climate Change: The Lancet Commission report", The Lancet. Feb 23; 393 (10173):791-846.

13. Taylor, S. 2019. "Editorial", Law in Context, 36 (2): 3-4.

14. United Nations General Assembly (UNGA). 2020a. Declaration on the Commemoration of the Seventy-Fifth Anniversary of the United Nations. https://undocs.org/A/75/L.1

15. United Nations General Assembly (UNGA). 2020b. Meeting Coverage. Seventy-Fifth Session, 3rd Meeting. GA/12267, 21 September, https://www.un.org/press/en/2020/ ga12267.doc.htm

16. Xu, H., Šavelka, J., and Ashley, K.D. 2020. "Using Argument Mining for Legal Text Summarization". In Villata, S., Harašta, J., and Křemen, P. (eds.) Legal Knowledge and Information Systems JURIX 2020: The Thirty-third Annual Conference, IOS Press: Amsterdam, pp. 184-193. 